\title{
Significance of hybrid learning model during COVID-19 pandemic at higher education institution
}

\author{
Mirela Müller ${ }^{1}$ \\ ${ }^{l}$ Faculty of Humanities and Social Sciences, University of Split
}

\begin{abstract}
Blended learning is any combination of traditional analog education with modern digital technologies. At its broadest, blended learning describes the introduction of computer labs, interactive whiteboards, and educational software to the learning process. When making recommendations for teaching at higher education institutions in the period of the COVID-19 pandemic with the application of anti-epidemic measures, among the important recommendations was the use of a hybrid learning model for students. Teachers were able to adjust the course of all forms of higher education only after determining that students, given the material and technical conditions and computer skills, can carry out certain activities at a distance.The research implicitly indicates which type of hybrid learning model proved to be the most effective in mastering the course outcome and successful implementation and realization of teaching during COVID 19. The results showed that most students wanted to have real-time instruction during the COVID-19 pandemic via the Big Blue Button rather than via the Google Classroom, and 94\% thought they would better adopt course outcomes than the classic hybrid teaching model. The possibility for the student to organize his / her own workspace, but also to cooperate with other students and teachers in acquiring knowledge, and this can be achieved with a precisely designed hybrid model of learning. It is the research that indicates the improvement of the quality of learning and the possibility of active participation of students in the learning process, which thus improves the learning outcomes.
\end{abstract}

Keywords: Blended learning, Big Blue Button, Google classroom, Wizer.me, teaching model 